\title{
Differential effects of glucose on modulation of emotional and nonemotional spatial memory tasks
}

\author{
APRAJITA MOHANTY \\ University of Illinois at Champaign-Urbana, Urbana, Illinois \\ and \\ ROBERT W. FLINT, JR. \\ College of Saint Rose, Albany, New York
}

\begin{abstract}
Research examining the memory-enhancing effects of glucose in humans has been limited to mnemonic tasks lacking affective components, even though glucose may be a mechanism for emotioninduced memory enhancement. This limitation does not permit analysis of interactions between the enhancing properties of emotional stimuli and glucose. Participants were administered either glucose or saccharin 15 min prior to completing a neutral or emotional spatial memory task. Performance under three glycemic conditions ( $100 \mathrm{mg} / \mathrm{kg}$ or $50 \mathrm{~g}$ glucose, or placebo) for the two sets of emotional stimuli revealed a significant interaction. Both $100-\mathrm{mg} / \mathrm{kg}$ and $50-\mathrm{g}$ doses of glucose resulted in impaired performance for emotional stimuli. For neutral stimuli, a 100-mg/kg dose enhanced memory, whereas a 50-g dose showed no effect. Results indicate that the enhancing effects of emotional stimuli may be attenuated by the consumption of glucose and suggest that recent food consumption should be considered in paradigms examining memory.
\end{abstract}

Research examining the influence of affect on mnemonic processes suggests that emotions have an enhancing effect on memory and that emotional events are associated with a greater persistence of memory for the event. Common examples of enhanced memory for emotional events include flashbulb memories (Brown \& Kulik, 1977), autobiographical memories (Reisberg, Heuer, McLean, \& O'Shaughnessey, 1988), eyewitness memory (Yuille \& Cutshall, 1989), and trauma-related memories in posttraumatic stress disorder (PTSD; McNally, 1997; Zeitlin \& McNally, 1991). Furthermore, laboratory studies have also demonstrated improved memory for emotional material, including emotional pictures (Bradley, Greenwald, Petry, \& Lang, 1992) and stories (Cahill \& McGaugh, 1995). It is important to recognize, however, that emotional memories in humans are inaccurate under certain circumstances and that a reevaluation of memory in the context of an accuracy-oriented approach should be considered (see Koriat, Goldsmith, \& Pansky, 2000, for review).

This study was completed in partial fulfillment of the requirements for A.M.'s master's degree at Minnesota State University, Mankato. The authors thank Ann Zak and Gregory A. Miller for comments on an earlier draft of this manuscript, Kari Murad for assistance with the graphical representations of these data, and Adam Johnson for assistance with data collection and analysis. Correspondence should be addressed to R. W. Flint, Jr., College of Saint Rose, Department of Psychology, 432 Western Ave., Albany, NY 12203-1490 (e-mail: flintr@ mail.strose. edu).
The mechanism(s) of the facilitating effects of emotional affect on mnemonic tasks remains unclear. One of the proposed mechanisms suggests that enhanced memory for emotional events may be modulated by activation of $\beta$-adrenergic stress hormone systems during and after an emotional experience (McGaugh, 1989). Nonhuman animal research indicates that epinephrine, an adrenergic stress hormone released in response to stressful training conditions (McCarty \& Gold, 1981), improves memory when administered immediately after training (Gold \& van Buskirk, 1975). Like other memory-modulating treatments, epinephrine's effects on memory are dose and time dependent (Gold \& van Buskirk, 1975). In a study of the role of beta-adrenergic stress hormones in arousalinduced memory modulation in humans, Cahill, Prins, Weber, and McGaugh (1994) reported enhanced retention for an emotional story in the placebo condition. Administration of propranolol, a $\beta$-adrenergic receptor antagonist, had no effect on memory for the neutral story, but attenuated the memory-enhancing effects of the emotional story. Together, these findings are strongly indicative of an important role of $\beta$-adrenergic receptor activation in arousal-related memory modulation.

One problem with the direct memory modulatory theory of epinephrine action is that this adrenal medullary hormone is not absorbed from the blood into the brain in appreciable amounts (Axelrod, Weil-Malherbe, \& Tomchick, 1959). A major physiological consequence of epinephrine is the liberation of glucose from the liver. It is possible that epinephrine effects on memory are mediated by 
release of glucose (Gold, 1987). The memory-enhancing effects of glucose, first demonstrated by Messier and White (1984) in rodents, have both dose- and time-dependent effects similar to those of epinephrine. Hall and Gold (1986) found that, in rats, plasma glucose levels show a footshock-intensity-related increase soon after inhibitory avoidance training. Furthermore, memory-enhancing doses of glucose and epinephrine result in increases in plasma glucose levels comparable to each other and to values seen after a high-intensity training footshock. Additional evidence indicates that some drugs block epinephrine-induced memory enhancement but fail to block glucose-induced enhancement (Gold, Vogt, \& Hall, 1986). This suggests that glucose may modulate memory at a step subsequent to epinephrine release.

These results can be incorporated into a biological system proposed by Gold (1987) that explains the formation of memory for emotional experiences. According to this system, stressors induce the release of epinephrine, which in turn releases glucose from the liver, resulting in increased circulating blood glucose levels. This glucose crosses the blood-brain barrier and enhances memory by interacting with central neuromodulators and neurotransmitters. Memory-modulating effects of glucose have been demonstrated in young adults (Benton \& Owens, 1993; Benton, Owens, \& Parker, 1994; Benton $\&$ Sargent, 1992), elderly participants (Gonder-Frederick et al., 1987; Manning, Parsons, Cotter, \& Gold, 1997; Manning, Stone, Korol, \& Gold, 1998), and individuals with memory pathology, such as probable senile dementia of the Alzheimer's type (Craft, Zallen, \& Baker, 1992; Manning, Ragozzino, \& Gold, 1993), schizophrenia(Newcomer et al., 1999), Down syndrome (Manning, Honn, Stone, Jane, \& Gold, 1998), and trauma-induced memory deficits (Pettersen \& Skelton, 2000).

A review of the aforementioned research suggests that both glucose and affective content have enhancing effects on memory and that the effect of emotional arousal on memory may be modulated by glucose. However, glucose does not always enhance memory. An important characteristic shared by memory modulators, including glucose, is that a memory-enhancing dose for a nonarousing training experience will impair memory for an arousing training experience (Gold, Vogt, \& Hall, 1986). In other words, adding the mnemonic improvement mediated by emotional arousal with the mnemonic improvement mediated by exogenous glucose administration would produce performance consistent with the downward slope of the inverted-U dose-response curve. Benton (1989) reported that increasing blood glucose levels improved performance on tasks that were less cognitively demanding, but not when the tasks were more demanding. In a more recent study, Parent, Varnhagen, and Gold (1999) demonstrated that glucose administration resulted in an increase in blood glucose levels above that associated with presentation of an emotional narrative. Furthermore, they reported that this glucose administration prevented the memory-enhancing effects of emotional arousal. In the present study, we investigated the effect of exogenously administered glucose on memory and whether these effects interact with the emotional nature of the task to affect memory. We predicted that glucose would affect performance differentially depending on the emotional nature of the task, enhancing performance for the neutral spatial memory task and impairing performance for the emotional spatial memory task.

\section{METHOD}

\section{Participants}

Seventy undergraduate and graduate students (48 female and 22 male with a mean age of $20.6 \pm 4.3$ years) at a state university received extra credit for participating. Experimental procedures were conducted across two consecutive days and all participants were tested between 8:00 and 11:00 a.m. Participants were instructed not to eat or drink after midnight prior to training and testing. Volunteers reporting a history of hypoglycemia, diabetes, phenylketonuria, or a family history of any of these disorders were excluded.

\section{Materials}

Stimulus materials used in the spatial memory task consisted of 16 emotional and 16 neutral pictures (see the Appendix) from the International Affective Picture System (IAPS; Lang, Ohman, \& Vaitl, 1988). Emotional pictures were selected to be highly negative and highly arousing. The $16 \times 21 \mathrm{~cm}$ colored IAPS pictures were laminated and presented simultaneously on a $4 \times 4$ grid, approximately $4 \mathrm{~cm}$ apart. The Self-Assessment Manikin (SAM; Lang, 1980) was used to assess the emotional reaction (arousal level, valence positive/ negative, and dominance level) of the participants to the pictures as a group (emotional or neutral) depending on the participant's group assignment.

Glucose drinks were prepared by mixing $100 \mathrm{mg} / \mathrm{kg}$ or $50 \mathrm{~g}$ of glucose (ADM Corn Processing) in $8 \mathrm{oz}$. of lemon-flavored water (Kool Aid). For the placebo drink, $23.7 \mathrm{mg}$ of saccharin (Sweet-10) was mixed in the same amount of lemon-flavored water. Blood glucose levels were assessed with a One Touch II Glucometer (Lifescan Inc., Mountain View, CA).

Two doses of glucose, the relative $100-\mathrm{mg} / \mathrm{kg}$ dose and the absolute 50 -g dose, were selected on the basis of the results from prior studies. In the majority of the nonhuman animal literature, researchers have employed relative bodyweight-dependent doses and found that $100 \mathrm{mg} / \mathrm{kg}$ appears to be an optimal memory-modulating dose, whereas the majority of the human studies have indicated that the absolute $50 \mathrm{~g}$ dose is optimal. The reason for this difference between the human and nonhuman animal literature is not clear. Thus, we chose to utilize both doses with the understanding that selecting one absolute and one relative dose will not allow for an analysis of any dose-response characteristics.

\section{Design and Procedure}

The Minnesota State University Mankato Institutional Review Board for research approved all procedures. Participants were weighed and randomly assigned to one of six groups on the basis of picture type (emotional $[\mathrm{E}]$ or neutral $[\mathrm{N}]$ ) and dose (saccharin $[\mathrm{S}]$, $100-\mathrm{mg} / \mathrm{kg}$ glucose [100] or $50 \mathrm{~g}$ glucose $[\mathrm{E}-\mathrm{S} n=14, \mathrm{E}-100 n=$ $10, \mathrm{E}-50 n=14, \mathrm{~N}-\mathrm{S} n=10, \mathrm{~N}-100 n=10, \mathrm{~N}-50 n=12]$ ). Baseline blood glucose levels were determined initially and 15 min after ingestion of the appropriate beverage. Participants were blind with respect to the contents of their drinks.

Acquisition trials were administered beginning approximately 15 min after consumption of the lemon-flavored beverage. Partici- 
pants were given $20 \mathrm{sec}$ to study the spatial arrangement of the pictures (emotional or neutral depending on group assignment) on the $4 \times 4$ grid. A 1-min intratrial interval was inserted between the study and test phase of each acquisition trial, during which participants counted backward aloud from 200 subtracting by 3 to prevent rehearsal. As a test of acquisition, participants were then given the pictures and asked to arrange them in the correct order on the $4 \times 4$ grid. The above acquisition study-test procedure was immediately repeated two more times, yielding a total of three acquisition trials. The pictures were arranged in a new pseudo-random order before being handed to the participant each time for correct placement during the test. The spatial arrangement of the pictures on the $4 \times 4$ grid was the same during each acquisition trial and for all participants. Time to complete each trial (from when participants were handed the pictures to when they placed the last one on the $4 \times 4$ grid) and the number of errors on each trial (number of pictures placed in the incorrect location on the $4 \times 4$ grid) were recorded as dependent measures.

Following the three acquisition trials, participants indicated their overall emotional reactions to the pictures on each dimension of the SAM scale. Approximately $24 \mathrm{~h}$ later, participants returned to the laboratory, where fasting baseline blood glucose levels were recorded and a recall test for the spatial memory task was administered. Participants were given the pictures arranged in a pseudo-random order (no study session) and were asked to place them in the correct order on the $4 \times 4$ grid. The time to complete the task and the number of errors, as described above, were recorded as dependent measures.

\section{RESULTS}

Results have been separated in accordance with the various procedures. An alpha level of $p \leq .05$ was used unless otherwise specified. All post hoc comparisons were conducted with simple effects or Fisher's LSD tests.

\section{Blood Glucose Levels}

Baseline and 15-min postconsumption blood glucose levels were analyzed using a $3 \times 2($ dose $\times$ time $)$ repeated measures analysis of variance (ANOVA). Results indicated a significant main effect of dose $[F(2,67)=10.87]$ and a dose $\times$ time interaction $[F(2,67)=31.70]$. Pairwise comparisons showed that the initial blood glucose levels of the three dose groups did not differ significantly. However, 15 min after glucose consumption, the 100$\mathrm{mg} / \mathrm{kg}$ and $50-\mathrm{g}$ doses had significantly higher glucose levels than did the saccharin group. Postconsumption blood glucose levels for the 50-g group were also significantly higher than the glucose level for $100-\mathrm{mg} / \mathrm{kg}$ group.

A one-way ANOVA for the baseline blood glucose levels at the time of the retention test was conducted to assess for baseline group differences. Results did not indicate any differences among the groups at the time of the retention test.

\section{Emotionality Ratings}

Overall emotionality ratings were provided for the emotional or neutral pictures, depending on group assignment, following the acquisition trials. Participants rated the emotional pictures as more negative $(M=2.55)$ than the neutral pictures $(M=6.06)$, more arousing $(M=$ $5.21)$ than the neutral pictures $(M=4.28)$, and more dominating $(M=5.37)$ than the neutral pictures $(M=4.03)$.
Independent sample $t$ tests on each dimension of the SAM scale indicated that emotional pictures were significantly more negative $[t(68)=10.37]$, more arousing $[t(68)=$ $1.99]$, and more dominating $[t(68)=3.10]$ than the neutral pictures. There was no effect of dose on the emotional reactions to the pictures.

\section{Spatial Memory Acquisition}

The acquisition data were collapsed across the three trials and analyzed using a factorial $2 \times 3$ (picture type $\times$ dose) ANOVA, which revealed a significant picture $X$ dose interaction $[F(2,64)=3.41]$. Visual inspection of the profile corresponding to this interaction (Figure 1A) shows that both groups receiving glucose made more errors than the saccharin group in the emotional picture condition. In contrast, in the neutral condition, the 100$\mathrm{mg} / \mathrm{kg}$ group made fewer errors, and the 50 -g group performed at a level similar to that of the saccharin group. Statistical analyses indicated that, in the emotional condition, the 50-g group made significantly more errors than did the saccharin group, but the difference between the $100-\mathrm{mg} / \mathrm{kg}$ group and saccharin group failed to reach significance. In the neutral picture condition, the 100$\mathrm{mg} / \mathrm{kg}$ group made significantly fewer errors than did the saccharin group, whereas the 50-g group showed no difference.

Figure 1B depicts the mean time taken by the three dose groups to complete the spatial memory task under the emotional and neutral picture conditions. The graph indicates that the saccharin group performed faster than both glucose groups in the emotional picture condition. However, in the neutral stimulus condition the $100-\mathrm{mg} / \mathrm{kg}$ group appears to have performed faster than the control group and the 50-g group seems to have performed more slowly. A $2 \times 3$ (picture type $\times$ dose) ANOVA revealed a main effect of picture $[F(1,64)=4.55]$, indicating that significantly more time was spent arranging the emotional pictures. A significant main effect of dose $[F(2,64)=$ 3.15] was also obtained. Post hoc tests revealed that the 50 -g group took significantly more time than either the saccharin $(p=.058)$ or the $100-\mathrm{mg} / \mathrm{kg}$ groups.

\section{Spatial Memory Retention}

Figure 1C shows that both glucose groups made more errors than did the saccharin group under the emotional condition. In the neutral condition, the saccharin control group made more errors than the $100-\mathrm{mg} / \mathrm{kg}$ glucose group but fewer errors than the 50-g group. A factorial 2 $\times 3$ (picture type $\times$ dose) ANOVA revealed a significant main effect of dose $[F(2,61)=3.10, p=.052]$ and a picture $\times$ dose interaction $[F(2,61)=5.65]$. Analyses revealed that in the emotional picture condition, both the $100-\mathrm{mg} / \mathrm{kg}$ and $50-\mathrm{g}$ groups made significantly more errors than did the placebo group. There were no differences between the treatment groups and the control group for the neutral picture condition. Similar trends in results were seen in time taken to complete the task, but differences did not reach statistical significance (Figure 1D). 

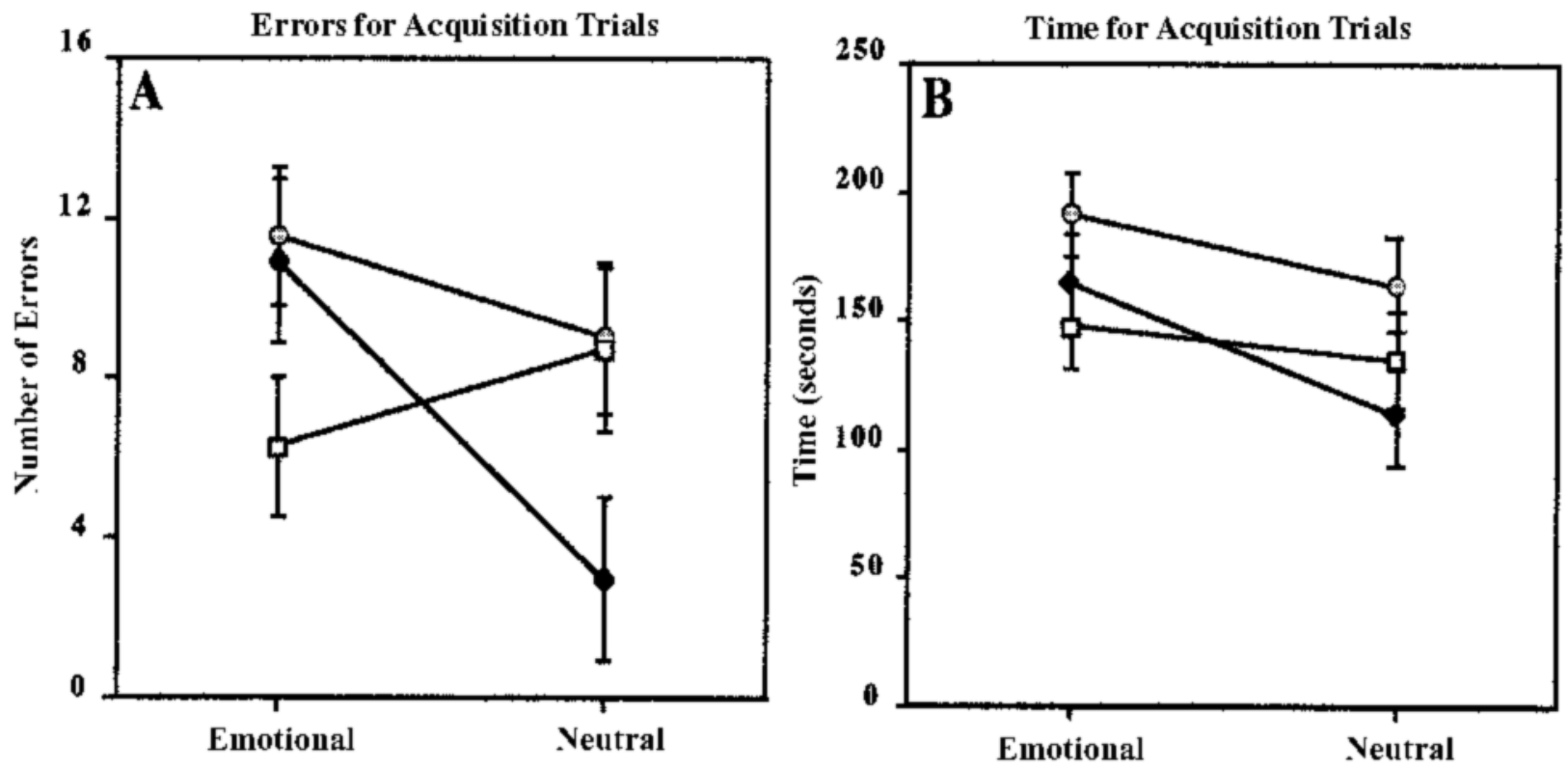

$\rightarrow-$ Saccharin $\rightarrow$ Glucose $(100 \mathrm{mg} / \mathrm{kg}) \rightarrow-$ Glucose $(50 \mathrm{gln})$
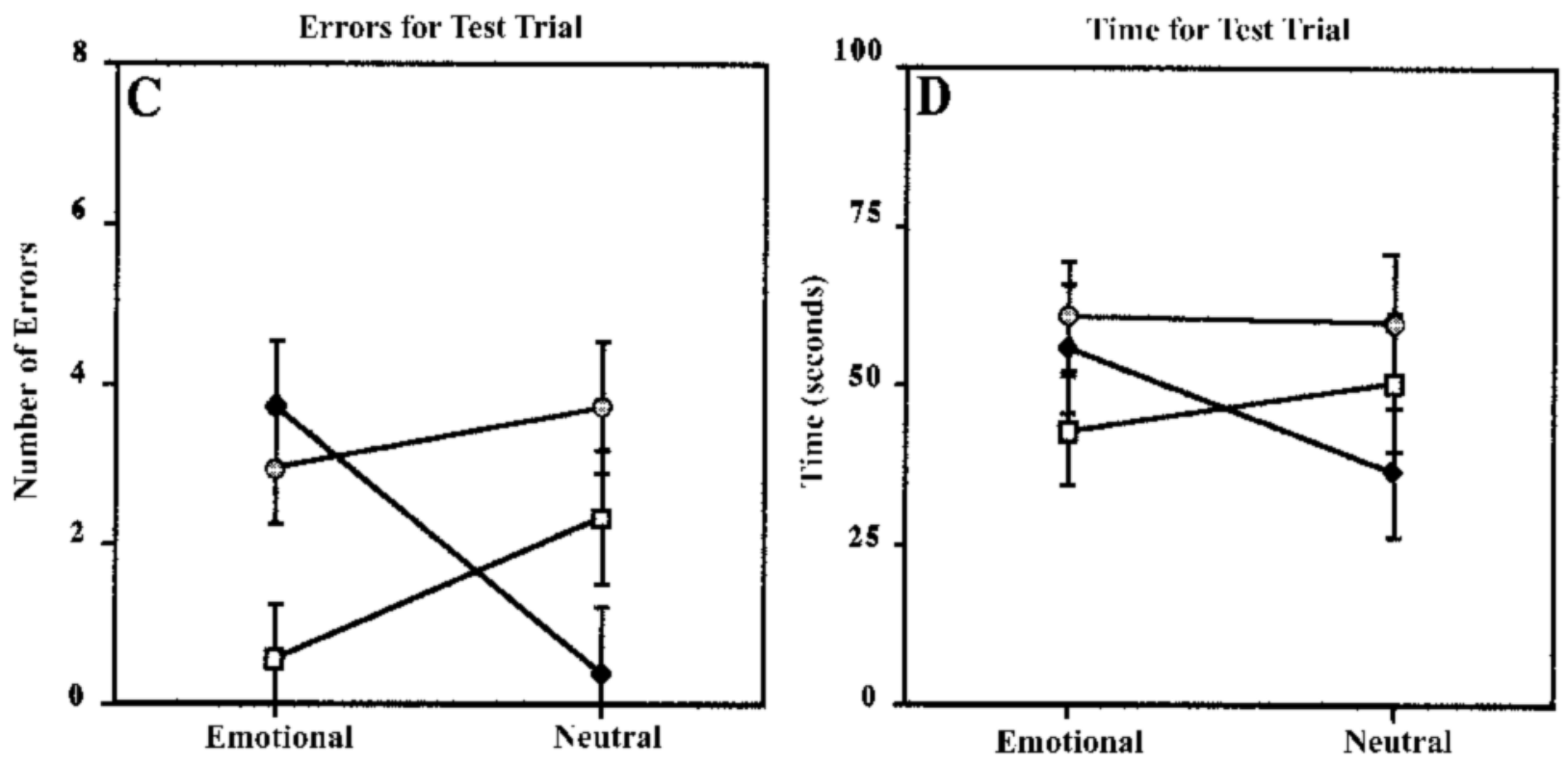

Figure 1. Panel A: Mean number of errors for the saccharin, 100-mg/kg, and 50-g glucose groups. Data have been collapsed across the acquisition trials for emotional and neutral pictures (error bars represent standard error of the mean). Panel B: Mean time to complete the task for each group during the acquisition trials. Data were collapsed across the trials for the emotional and neutral pictures (error bars represent standard error of the mean). Panel C: Mean number of errors on the retention test for the saccharin, 100-mg/kg, and 50-g glucose groups separated for emotional and neutral pictures (error bars represent standard error of the mean). Panel D: Mean time for each dose group to complete the retention test for both the emotional and neutral pictures (error bars represent standard error of the mean).

\section{DISCUSSION}

Empirically, the aim of the present study was twofold: (1) to examine the effect of different doses of glucose on memory and (2) to investigate whether these effects interact with the emotional nature of the task to determine memory for the task. Consistent with the hypotheses, the findings of this study demonstrate that glucose administration may enhance memory performance, and that the effects of exogenously administered glucose may interact with the emotionality of the task to modulate performance. The significant glucose $\times$ emotion interaction indicates that the effect of glucose on memory for a task must be interpreted in terms of the emotional content of the 
task. In our study, both $100-\mathrm{mg} / \mathrm{kg}$ and 50 -g doses of glucose impaired retention, and the 50-g dose also impaired acquisition of the spatial memory task with emotional stimuli. In contrast, $100 \mathrm{mg} / \mathrm{kg}$ of glucose enhanced acquisition for neutral stimuli. Although not all of the statistical comparisons across the dependent measures reached significance, the general pattern of results for both errors and time to complete the spatial memory task support the modulatory and interactive effects of glucose and affect. One likely explanation for the failure of some comparisons to reach significance is the presence of ceiling effects, where participants were making very few errors and performing the task very quickly.

Gold (1991) concluded that glucose is a memory modulator with a positive valence (i.e., it enhances memory irrespective of the kind of test employed), and Wenk (1989) labeled glucose as a cognitive enhancer. However, Gold et al. (1986) reported that glucose, which enhanced memory for a low footshock, had an impairing effect on memory for a more intense footshock in rodents. This finding is consistent with our study and suggests that the arousalrelated responses to the aversive training event interacted with the exogenously administered treatment to decrease performance on the task. It could be said that Gold et al. manipulated the emotionality of the training event by using different footshock intensities. In the present study, we manipulated the emotionality of the task by using two sets of standardized stimuli, emotional and neutral, that produced results reminiscent of those reported by Gold et al.

The combined effects of arousing stimuli and glucose on memory could be interpreted in terms of an inverted-U dose-response curve, exhibited by many memory modulators, including glucose (Parsons \& Gold, 1992). Using the inverted-U curve, Yerkes and Dodson (1908) described the relationship between arousal and memory, stating that low and high arousal levels are related to poorer performance and that moderate levels are associated with optimal performance. The inverted-U dose-response curve has been used to explain clinical disorders exhibiting memory pathology: People who experience trauma develop PTSD, and those who experience excessive trauma develop amnesia (Pitman, 1989; Pitman \& Orr, 1995). In the present study, the arousal-related changes resulting from the emotional nature of the task, coupled with the exogenously administered glucose, may have produced changes that attenuated the enhancing effects of the treatments when administered individually. Support for this hypothesis comes from a recent study by Parent et al. (1999) demonstrating that a memory-enhancing emotionally arousing narrative resulted in elevated blood glucose levels in humans.

The inverted-U dose-response curve interpretation suggests that combined emotional arousal and exogenous glucose pushed the modulatory mechanism(s) past the apex toward baseline on the downward slope of the curve. The components of emotional arousal in this hypothetical explanation are not limited to glucose. Epinephrine, in addition to modulating memory itself, causes the release of glucose from the liver and the concomitant release of hyperglycemia hormone, glucagon, and inhibi- tion of hypoglycemichormone, insulin (Kraus-Friedman, 1984). Aversive learning situations may also activate adrenocortical stress hormone systems (e.g., glucocorticoids), which have been shown to enhance memory (Cahill, Roozendaal, \& McGaugh, 1997). Roozendaal, Carmi, and McGaugh (1996) even demonstrated that stressinduced increases in plasma glucocorticoid levels are required to induce the memory-enhancing effects of epinephrine. Finally, Clark, Naritoku, Smith, Browning, and Jensen (1999) have recently demonstrated that stimulation of the vagus nerve in humans enhances recognition memory. This finding provides considerable support for the hypothesis from the rodent literature indicating that vagal stimulation modulates memory storage (Clark, Krahl, Smith, \& Jensen, 1995; Clark et al., 1998), and may be the pathway through which some of the aforementioned neuromodulators influence memory. Thus, the complexity of the potential neurobiological and psychological mechanisms makes it difficult to comment on the exact mechanism of glucose action in emotional memory. It is clear, however, that the modulatory effects of arousing stimuli and emotional events may be offset or degraded by moderate increases in plasma glucose levels. This appears to be the first report of such an interaction in the human literature and should significantly impact research on both emotional memories and the memory modulatory effects of arousal-related neurochemicals.

\section{REFERENCES}

Axelrod, J., Weil-Malherbe,H., \& Tomchick, R. (1959). The physiological disposition of ${ }^{3} \mathrm{H}$-epinephrine and its metabolite metaepinephrine. Journal of Pharmacology \& Experimental Therapeutics, 127, 251-256.

BENTON, D. (1989). Dietary sugar hyperactivity and cognitive functioning. Journal of Applied Nutrition, 41, 13-22.

Benton, D., \& Owens, D. S. (1993). Blood glucose and human memory. Psychopharmacology, 113, 83-88.

Benton, D., Owens, D. S., \& Parker, P. Y. (1994). Blood glucose influences memory and attention in young adults. Neuropsychologia, 32, 595-607.

Benton, D., \& SARgent, J. (1992). Breakfast, blood glucose, and memory. Biological Psychology, 33, 207-210.

Bradley, M. M., Greenwald, M. K., Petry, M., \& Lang, P. J. (1992). Remembering pictures: Pleasure and arousal in memory. Journal of Experimental Psychology: Learning, Memory, \& Cognition, 18, 379-390.

BRown, R, \& KulIK, J. (1977). Flashbulb memories. Cognition, 5, 73-99.

CAhill, L., \& McGaugh, J. L. (1995). A novel demonstration of enhanced memory associated with emotional arousal. Conscious Cognition, 4, 410-421.

Cahill, L., Prins, B., Weber, M., \& McGaugh, J. L. (1994). $\beta$-Adrenergic activation and memory for emotional events. Nature, 371, 702-704.

Cahill, L., RoozendaAl, B., \& McGaugh, J. L. (1997). The neurobiology of memory for aversive emotional events. In M. E. Bouton \& M. S. Fanselow (Eds.), Learning, motivation, and cognition: The functional behaviorism of Robert C. Bolles (pp. 369-385). Washington, DC: American Psychological Association.

Clark, K. B., Krahl, S. E., Smith, D. C., \& Jensen, R. A. (1995). Post-training unilateral vagal stimulation enhances retention performance in the rat. Neurobiology of Learning \& Memory, 63, 213-216.

Clark, K. B., Naritoku, D. K., Smith, D. C., Browning, R. A., \& JENSEN, R. A. (1999). Enhanced recognition memory following vagus nerve stimulation in human subjects. Nature Neuroscience, 2, 94-98.

Clark, K. B., Smith, D. C., Hassert, D. L., Browning, R. A., NariTOKU, D. K., \& JeNSEN, R. A. (1998). Posttraining electrical stimulation of vagal afferents with concomitant vagal efferent inactivation 
enhances memory storage processes in the rat. Neurobiology of Learning \& Memory, 70, 364-373.

Craft, S., Zallen, G., \& BaKer, L. D. (1992). Glucose and memory in senile dementia of the Alzheimer type. Journal of Clinical \& Experimental Neuropsychology, 14, 253-267.

Gold, P. E. (1987). Sweet memories. American Scientist, 75, 151-155.

GoLd, P. E. (1991). An integrated memory regulation system: From blood to brain. In R. C. A. Frederickson, J. L. McGaugh, \& D. L. Felten (Eds.), Peripheral signaling of the brain (pp. 391-419). Toronto: Hogrefe \& Huber.

Gold, P. E., \& VAN BUSKIRK, R. B. (1975). Facilitation of time-dependent memory processes with posttrial epinephrine injections. Behavioral Biology, 13, 145-153.

Gold, P. E., Vogt, J., \& HALL, H. L. (1986). Posttraining glucose effects on memory: Behavioral and pharmacological characteristics. Behavioral \& Neural Biology, 46, 145-155.

Gonder-Frederick,L. A., Hall, J. L., Vogt, J., Cox, D. J., Green, J., \& Gold, P. E. (1987). Memory enhancement in elderly humans: Effects of glucose ingestion. Physiology \& Behavior, 41, 503-504.

HALl, J. L., \& Gold, P. E. (1986). The effects of training, epinephrine and glucose injections on plasma levels in rats. Behavioral \& Neural Biology, 46, 156-167.

Koriat, A, Goldsmith, M., \& Pansky, A. (2000). Toward a psychology of memory accuracy. Annual Review of Psychology, 51, 481-537.

Kraus-Friedman, N. (1984). Hormonal regulation of hepatic gluconeogenesis. Physiological Reviews, 64, 170-259.

LANG, P. J. (1980). Behavioral treatment and bio-behavioral assessment: Computer applications. In J. B. Sidowski, J. H. Johnson, \& T. A. Williams (Eds.), Technology in mental health care delivery systems (pp. 119-137). Norwood, NJ: Ablex Publishing.

LANG, P. J., OHMAN, A., \& VAITL, D. (1988). The International Affective Picture System [Photographic slides]. Gainesville: University of Florida Center for Research in Psychophysiology.

Manning, C. A., Honn, V. J., Stone, W. S., Jane, S. J., \& Gold, P. E. (1998). Glucose effects on cognition in adults with Down's Syndrome. Neuropsychology, 12, 479-484.

Manning, C. A., Parsons, M. W., Cotter, E. M., \& Gold, P. E. (1997). Glucose effects on declarative and nondeclarative memory in healthy elderly and young adults. Psychobiology, 25, 103-108.

Manning, C. A., Ragozzino, M. E. \& Gold, P. E. (1993). Glucose enhancement of memory in patients with probable senile dementia of the Alzheimer's type. Neurobiology of Aging, 14, 523-528.

Manning, C. A. Stone, W. S. Korol, D. L., \& Gold, P. E. (1998). Glucose enhancement of 24-h memory retrieval in healthy elderly humans. Behavioural Brain Research, 93, 71-76.

McCARTy, R., \& Gold, P. E. (1981). Plasma catecholamines: Effects of footshock level and hormonal modulators of memory storage. Hormones \& Behavior, 15, 168-182.

McGAUGH, J. L. (1989). Involvement of hormonal and neuromodulatory systems in the regulation of memory storage. Annual Review of Neuroscience, 12, 255-287.

MCNALLY, R. J. (1997). Implicit and explicit memory for traumarelated information in PTSD. In R. Yehuda \& A. C. McFarlane (Eds.), Psychobiology of posttraumatic stress disorder (Annals of the New York Academy of Sciences, Vol. 821, pp. 219-224). New York: New York Academy of Sciences.

Messier, C., \& White, N. M. (1984). Contingent and non-contingent actions of sucrose and saccharin reinforcers: Effects of taste preference and memory. Physiology \& Behavior, 32, 195-203.

Newcomer, J. W., Craft, S., Fucetola, R., Moldin, S. O., Selke, G., Paras, L., \& Miller, R. (1999). Glucose-induced increase in memory performance in patients with schizophrenia. Schizophrenia Bulletin, 25, 321-335.

Parent, M. B., Varnhagen, C., \& Gold, P. E. (1999). A memoryenhancing emotionally arousing narrative increases blood glucose levels in human subjects. Psychobiology, 27, 386-396.

Parsons, M. W., \& Gold, P. E. (1992). Glucose enhancement of memory in elderly humans: An inverted-U dose-response curve. Neurobiology of Aging, 13, 401-404.

Pettersen, J. A., \& Skelton, R. W. (2000). Glucose enhances longterm declarative memory in mildly head-injured varsity rugby players. Psychobiology, 28, 81-89.
Pitman, R. K. (1989). Post-traumatic stress disorder, hormones, and memory. Biological Psychiatry, 26, 221-223.

PItMAn, R. K., \& OrR, S. P. (1995). Psychophysiology of emotional memory networks in posttraumatic stress disorder. In J. L. McGaugh, N. M. Weinberger, \& G. S. Lynch, Brain and memory: Modulation and mediation of neuroplasticity (pp. 75-83). New York: Oxford University Press.

Reisberg, D., Heuer, F., McLean, J., \& O'Shaughnessey, M. (1988). The quantity, not the quality, of affect predicts memory vividness. Bulletin of Psychonomic Society, 26, 100-103.

RoozendaAl, B., Carmi, O., \& McGaugh, J. L. (1996). Adrenocortical suppression blocks the memory-enhancing effects of amphetamine and epinephrine. Proceedings of the National Academy of Sciences, 93, 1429-1433.

WENK, G. L. (1989). An hypothesis on the role of glucose in the mechanism of action of cognitive enhancers. Psychopharmacology, 99, 431-438.

Yerkes, R. M., \& Dodson, J. D. (1908). The relation of strength of stimulus to rapidity of habit formation. Journal of Comparative Neurology \& Psychology, 18, 458-482.

Yuille, J. C., \& Cutshall, J. L. (1989). Analysis of the statements of victims, witnesses, and suspects. In J. C. Yuille (Ed.), Credibility assessment (pp. 175-191). Dordrecht, The Netherlands: Kluwer.

Zeitlin, S. D., \& McNALly, R. J. (1991). Implicit and explicit memory bias for threat in post-traumatic stress disorder. Behavior Research \& Therapy, 29, 451-457.

\section{APPENDIX}

IAPS Slide Numbers and Descriptions

Slide No Description

Neutral Pictures

1670

5500

7050

7060

7080

7090

7100

7150

7170

7500

7190

7020

7010

7550

2200

2190

Cow

Mushroom

Hair dryer

Trash can

Fork

Book

Fire hydrant

Umbrella

Lightbulb

Building

Watch

Fan

Basket

Office

Neutral adult

Man

3170

9050

7380

1120

1300

3010

3000

3053

3071

3230

3150

6230

6313

9300

3130

9410

Emotional Pictures
Baby with tumor
Plane crash
Pizza with roaches
Snake
Pit bull
Mutilation
Mutilated face
Burn victim
Throat slash
AIDS patient
Mutilated hand
Aimed gun
Woman attacked
Filthy toilet
Mutilated body
Man with child

(Manuscript received July 21, 2000; revision accepted for publication January 2, 2001.) 